\title{
An Inverted Co-Flow Diffusion Flame For Producing Soot
}

\author{
Christopher Stipe ${ }^{1}$, Brian S. Higgins ${ }^{2}$, Donald Lucas ${ }^{3 *}$, \\ Catherine P. Koshland ${ }^{1}$, and Robert F. Sawyer ${ }^{1}$ \\ ${ }^{1}$ University of California at Berkeley \\ ${ }^{2}$ California Polytechnic State University, San Luis Obispo \\ ${ }^{3}$ Lawrence Berkeley National Laboratory
}

Keywords: Soot, Particle Generation, Flame

* Corresponding Author:

Donald Lucas

70-108B

LBNL

Berkeley, CA 94720

D lucas@1bl.gov

510-486-7002

510-486-7303 (FAX) 


\begin{abstract}
We developed an inverted, co-flow, methane/air/nitrogen burner that generates a wide range of soot particles sizes and concentrations. By adjusting the flow rates of air, methane, and nitrogen in the fuel, the mean electric mobility diameter and number concentration are varied. Additional dilution downstream of the flame allows us to generate particle concentrations spanning those produced by spark-ignited and diesel engines: particles with mean diameters between 50 and $250 \mathrm{~nm}$ and number concentrations from $4.7 \cdot 10^{4}$ to $10^{7} \mathrm{~cm}^{-3}$. The range of achievable number concentrations, and therefore volume concentrations, can be increased by a factor of 30 by reducing the dilution ratio. These operating conditions make this burner valuable for developing and calibrating diagnostics as well as for other studies involving soot particles.
\end{abstract}

\title{
Introduction
}

The significant health and environmental effects associated with combustion generated particulate matter create the need for reproducible and controllable particle sources that share key characteristics with the practical systems. We developed a low-cost particle generation system to aid in the development of new measurement techniques, calibration of existing techniques, and as a source for particle inhalation health studies. The inverted burner system we developed produces particles over a large size (50 to $250 \mathrm{~nm}$ ) and concentration range. The size distribution of the soot particles produced in the inverted flame is controlled by two means: adjusting the fuel and co-flow air flow rates and/or by diluting the fuel jet with nitrogen. The final concentration is controlled by additional dilution downstream of the flame. 
Current sources of combustion-generated particles used for diagnostic development include various burner arrangements such as opposed flow and flat flame burners and engines. A tremendous amount of studies have been conducted on soot formation within the flame in opposed flow, co-flow, and flat flame burners (e.g., Fenimore et al., 1957, Axelbaum et al., 1988, Bohm et al., 1988, Puri et al., 1993, Kang et al., 1997, Du et al., 1998, Stanmore et al., 2001). Our objective was to create a source of particles that remain in the post-flame gases. A commercial instrument for soot generation using a combustion source is available (http://www.sootgenerator.com) based on the work of Girling et al. (1990) and Cleary et al. (1992). Another method employs a spark discharge to produce particles from graphite (http://www.palas.de/engl/produkte/trockd.htm). Engines are often used as a source of soot particles, but they are not ideal for developing diagnostics. Hour to hour fluctuations exceeding $20 \%$ are common, and day to day variations are even greater (Kayes and Hochgreb, 1998). The engine break-in-period can exceed 200 hours and achieving a steady-state operating condition takes 30 minutes or longer (Graskow et al., 1998). Also, a long break in period is suggested after an oil change, as the oil condition appears to be an important factor in the emission of small particles (Andrews et al., 1993).

Our system operates differently from those described, and the apparatus can be easily assembled in most laboratories from standard parts. The operating conditions are changed quickly and accurately by adjusting gas flow rates. A remaining question concerning particulate matter toxicity is the relative importance of the size and chemical composition of inhaled particles (Health Perspectives, April 2001). The inverted burner produces 
particles in the size range that is capable of penetrating deeply into the lungs and is an excellent source for an inhalation study because the size, concentration, and chemical composition can be controlled. To maximize the concentration of particles in a specific size range, the peak diameter of the particles can be varied from 50 to $250 \mathrm{~nm}$. In our laboratory, we are adding metals at different locations in the burner system to produce multi-composition particles. In addition, various volatile and semi-volatile organic compounds, which are presumed to cause much of the adverse health effects associated with exposure to particles, could be adsorbed on the particles after exiting the flame.

\section{Background}

Soot formation in diffusion flames has been studied in great detail (e.g., Wagner, 1979, Glassman, 1988, Du and Axelbaum, 1995, Angrill et al., 2000, Xu and Faeth, 2001, Snelling et al., 2004). Fuel dilution and flame temperature produce an individual effect on the formation of soot in the flame. Axelbaum and Law (1990) studied a co-flow ethylene diffusion flame to determine the separate effects of temperature and dilution. The soot volume fraction, measured by light extinction, of pure $\mathrm{C}_{2} \mathrm{H}_{4}$ was approximately twice that of a diluted fuel mixture of $50 \% \mathrm{C}_{2} \mathrm{H}_{4} / 50 \% \mathrm{~N}_{2}$. In their first experiment, both the reduction in flame temperature and dilution of the fuel caused the soot reduction. To determine the effect only from dilution, argon was added to the oxidizer side of the coflow flame with the $50 \% \mathrm{C}_{2} \mathrm{H}_{4} / 50 \% \mathrm{~N}_{2}$ fuel mixture so that the flame temperature equaled the $100 \% \mathrm{C}_{2} \mathrm{H}_{4}$ fuel case. By comparing the results of the two experiments, they determined that the soot volume fraction was affected more by dilution of fuel than by 
the reduction in flame temperature. Ultimately, the soot volume fraction varied linearly with the mole fraction of fuel in the fuel jet for mole fractions between 0.2 and 1.0.

Gulder and Snelling (1993) used another novel approach to study the effects of temperature and dilution on soot formation in an over-ventilated, co-flow, ethylene laminar diffusion flame. In one experiment, the fuel was diluted with nitrogen. The reduction of the soot volume fraction was again due to combined effects of diluting the fuel and a reduction of the flame temperature. In a second experiment, the effect of temperature was isolated by varying the temperature of the reactants from 298 to $623 \mathrm{~K}$ without diluting the fuel. Dilution had a greater effect than temperature in the range of fuel dilution from 0 to 0.7 . At diluent fractions above 0.7 , temperature effects dominate soot formation.

These two groups studied soot formation within the flame. In our work, we study the effects of overall equivalence ratio and nitrogen dilution of the fuel on the soot measured in the post flame gases, thereby creating a source of soot for diagnostic development and inhalation studies. To develop a diagnostic technique for measuring particle size, the particle source must be controllable to generate particles of various sizes and concentrations. Within reasonable ranges, volume fraction can be easily controlled by dilution. Controlling particle diameter is more difficult. In our study, we developed a system where both the mean particle diameter and the soot volume fraction are readily varied. 


\section{Experimental Apparatus}

The particle source, consisting of an inverted, non-premixed flame attached to a flow reactor, is schematically represented in Fig. 1. The methane/nitrogen/air flame is contained in a 48.3-cm long, 4.75-cm diameter quartz tube. Downstream of the quartz tube section is a $140-\mathrm{cm}$ long stainless steel tube of the same diameter.

Methane, controlled by a Teledyne Hastings-Raydist mass flow controller, flows through the 1.9-cm diameter inner tube. A rotometer controls the flow rate of nitrogen fuel diluent that is mixed with the methane well upstream of the burner. Combustion air, controlled by another mass flow controller, is injected in the annular region between the methane fuel jet and the outer quartz tube.

The burner was designed to maximize flame stability while still having the ability to control the mean particle diameter. Initial repeatability tests showed that with the flame in an upright position, the soot concentrations varied by as much as $30 \%$. Flame flicker, which causes the large variation of soot escaping the flame, affects the shape of flame tip, the oxidation rate of soot, and the amount of soot that escapes through the flame (Shaddix and Smyth, 1996). With the inverted design, the upward force of buoyant hot products maintains a uniform downward flow in the flow reactor, thus stabilizing the flame (Bedat and Cheng, 1996).

The total flow of gases through the quartz tube is limited to a relatively narrow range. The co-flow air flow rate is held constant for all conditions at $17.5 \mathrm{lpm}$; at flow rates 
lower than $16.5 \mathrm{lpm}$ a bi-modal distribution of particles is observed. The flow rate of fuel is varied from 1.2 to $1.4 \mathrm{lpm}$, corresponding to net equivalence ratios from 0.65 to 0.78 . Under these conditions, the flame is approximately $30 \mathrm{~cm}$ long and bright yellow. The flame exhibits turbulent behavior at a fuel flow rate of approximately $2.5 \mathrm{lpm}$. The flame is stabilized on an annular bluff-body obstruction. We experimented with several sizes and profiles and found that if the bluff-body was too small, the flame heated it excessively, causing the methane to preheat and flow up the side of the flow reactor, leading to an asymmetric flame. Although this did not radically alter the performance of the flow reactor, care was taken to assure this did not occur in the final design. The final flame holder has an inner diameter of $1.9 \mathrm{~cm}$.

Attached to the exit of the quartz tube is a $140-\mathrm{cm}$ long, $4.75-\mathrm{cm}$ diameter, stainless steel tube. The stainless tube has two ports located 5 and $137 \mathrm{~cm}$ downstream from the quartz section. Secondary air is axially injected, at a dilution ratio of 3 to 1 , through the upstream port to dilute, cool, and mix the exhaust. The diluted exhaust is sampled from the downstream port. The remaining products of combustion exit the flow reactor into the laboratory ventilation system.

An ejector pump extracts $2 \mathrm{lpm}$ from the diluted exhaust through the downstream port. The compressed air flow rate to the ejector pump is $20 \mathrm{lpm}$, producing a dilution ratio of 10:1. A diffusion denuder, between the sample port and the ejector pump, removes water vapor and gas phase hydrocarbons. The denuder consists of 14 sets of activated charcoal sheets in an arrangement described by Tang et al. (Tang et al., 1994). This ensures that 
water will not condense in the Scanning Mobility Particle Sizer system (SMPS) and cause measurement errors (Kayes and Hochgreb, 1998). The particles exiting the denuder do not have measurable $\mathrm{C}_{2}$ or $\mathrm{CH}$ emission peaks when photofragmented with $193 \mathrm{~nm}$ light (Damm et al., 2001). This suggests that the soot does not have significant amounts of unsaturated or aromatic hydrocarbons, as these species exhibit much larger $\mathrm{C}_{2}$ or $\mathrm{CH}: \mathrm{C}$ emission ratios. As measured by FTIR spectroscopy, the denuder efficiently ( $>97 \%)$ removes hydrocarbons larger than methane from the gas flow, as well as semi-volatile species from the surface of the particles that vaporize during transport through the denuder. A significant fraction of the particles ( 95\%) exit the denuder (Damm, 2001). The denuder was recharged nightly by heating and drawing room air through the chamber.

In total, the exhaust gases are diluted 30:1, including the primary dilution air injected in the stainless steel flow reactor. The sample is at room temperature for SMPS analysis. The SMPS system, operating in underpressure mode, draws $0.3 \mathrm{lpm}$ from the total diluted flow. The remainder of the exhaust flows to the ventilation system. Number concentrations and size distributions are measured with a TSI model 3071A Differential Mobility Ananlyzer (DMA) in conjunction with a model 3025A condensation particle counter (CPC). Mobility diameters from the SMPS system are presented without corrections for the non-spherical nature of the soot particles. 


\section{Results and Discussion}

Previous studies note the difficulty of obtaining repeatable SMPS measurements of soot particles. The problems can be traced to long stabilization times, transient or cyclic operation, or condensation of combustion water in the sample lines (Kayes and Hochgreb, 1998, Graskow et al., 1998). Any of these conditions may individually alter the SMPS results. To reduce these problems, we designed our flow reactor and sampling system to limit flow variability and condensation. We allow 10 minutes after changing operating conditions before taking data. Figure 2 shows the number concentration for ten subsequent runs taken over 6 hours of operation at one burner condition, and illustrates the stability of the system. The standard deviation of the number concentration of particles for these ten scans is less than $4 \%$.

Engine researchers have long known that the size distribution of particles depends on sampling conditions such as dilution ratio, residence times, and temperature histories (e.g., MacDonald et al., 1980, Plee and MacDonald, 1980). To determine the effect of dilution on our system, secondary dilution air is added $5 \mathrm{~cm}$ downstream of the quartz flame enclosure. At a methane flow rate of $1.3 \mathrm{lpm}$ and co-flow air flow rate of $17.5 \mathrm{lpm}$, secondary dilution air is varied from a dilution ratio of 1 to 3.5 with all other conditions held constant. The temperature of the diluted exhaust gases varied from 123 to $210^{\circ} \mathrm{C}$. These dilution conditions had only minor effects on the mean diameter and dilution corrected volume concentration of particles. The maximum change in the mean diameter from the average is $4 \%$, and the maximum variation in the total volume concentration 
(corrected for dilution) is also approximately 4\%. FTIR measurements of the exhaust gases show that $<1 \mathrm{ppm}$ of gaseous unburned hydrocarbons is emitted from this flame.

Figure 3 shows the effect of adding nitrogen to the methane fuel jet on the size distribution of soot particles. Nitrogen comprises from 0 to $40 \%$ of the methane flow rate by volume. As the nitrogen dilution is increased, the flame temperature is cooled, and the residence time of the particulate in the flame is slightly reduced. The reduction in flame temperature reduces both the soot formation and oxidation rates, and the dilution of the fuel reduces coagulation rates (Axelbaum and Law, 1990, Gulder and Snelling, 1993). The trends in the mean electric mobility diameter and number concentration of soot as a function of nitrogen dilution are illustrated in Fig. 4. The mean electric mobility diameter of the particles decreases from 195 to $60 \mathrm{~nm}$ as the nitrogen dilution increases from 0 to $40 \%$. The overall number concentration of particulates remain relatively constant at $4 \cdot 10^{5}$ $\mathrm{cm}^{-3}$ until the dilution exceeds $30 \%$, where it begins to decrease rapidly. For these experiments, the overall dilution ratio is held constant at $30: 1$, but could be varied by changing the secondary dilution air flow rate or the dilution by the ejector pump to create a larger range of number concentrations.

A similar chart of results in Fig. 5 shows the variation of the size distribution of the soot particles as a function of the net equivalence ratio. The co-flow air flow rate is held constant, and the fuel flow rate is adjusted to vary the overall equivalence ratio from 0.64 to 0.82 . The resulting effects are an increase in the mean electric mobility diameter and an increase in the number concentration of particles. As the net equivalence ratio is 
increased, the flame temperature increases, but the residence time of a particle traveling through the flame remains relatively constant because the flame height is proportional to the velocity of the fuel jet. Both the production and destruction of soot are sensitive to the flame temperature. In this case, the increase in temperature causes more soot to be produced than destroyed by oxidation at the flame front (Axelbaum and Law, 1990, Gulder and Snelling, 1993). The trends in the mean electric mobility diameter and the number concentration of particles are illustrated in Fig. 6. The effect of net equivalence ratio on the soot is quite different than the effect from $\mathrm{N}_{2}$ dilution. Both the mean electric mobility diameter and the number concentration of particles increase as the net equivalence ratio increases. The range of mean electric mobility diameters created is 50 to $250 \mathrm{~nm}$. At equivalence ratios larger than 0.82 , the distribution of particles become bimodal. The number concentration of particles increases linearly with net equivalence ratio from $4.7 \cdot 10^{4}$ to $7.6 \cdot 10^{5} \mathrm{~cm}^{-3}$. The number concentration may also be controlled by dilution as in the previous case.

A diagram of the observed and potentially achievable volume concentrations and mean particle diameters is given in Fig. 7. The measured range of mean particle diameters is 50 to $250 \mathrm{~nm}$, with corrected particle volume concentrations between $2.7 \mathrm{ppt}$ to $1.4 \mathrm{ppb}$. By reducing the dilution ratio, the range of concentrations could be increased by a factor of 30 to a maximum concentration of approximately $40 \mathrm{ppb}$. The usefulness of this soot particle source is apparent by comparing the achievable concentrations from the burner to those from practical combustion systems, including spark-ignited and diesel automobile engines (Hall et al., 1998). The concentration of soot produced by four light duty diesel 
automobiles under five different driving conditions studied by Hall et al. ranged from 20 to $300 \mathrm{mg} / \mathrm{m}^{3}$ depending on the vehicle and driving condition. Concentrations for light duty gasoline vehicles were approximately 100 times lower. For both diesel and gasoline powered vehicles $99 \%$ of the number of particles produced had a diameter less than 1 $\mu \mathrm{m}$.

This flame could serve as a source of particles for developing or comparing particle sizing techniques. It was recently used to determine the fragmentation fluorescence signal dependence on particle size (Stipe et al., 2002). In addition, this source would be useful for Tandem-DMA studies because the peak of the size distribution is readily moved to maximize the number of particles in the selected size range.

\section{Acknowledgments}

This work was supported by the Environmental Health Sciences Superfund Basic Research Program (Grant Number P42 ESO 47050-01) from the National Institute of Environmental Health Sciences, NIH, with funding provided by the EPA. Its contents are solely the responsibility of the authors and do not necessarily represent the official views of NIEHS, NIH, or EPA. 


\section{References}

1. C. P. Fenimore, G. W. Jones, and G. E. Moore, Proc. Combust. Instit., 6, 242-247 (1957).

2. R. L. Axelbaum, W. L. Flower, and C. K. Law, Combust. Sci. and Tech., 61, 51-73. (1988).

3. H. Bohm, D. Hesse, H. Jander, B. Luers, J. Pietscher, H. G. Wagner, and M. Weiss, Proc. Combust. Instit., 22, 403-411 (1988).

4. R. Puri, T. F. Richardson, R. J. Santoro, and R. A. Dobbins, Combustion \& Flame. v 92 n 3, 320-333 (1993).

5. K. T. Kang, J. Y. Hwang, S. H. Chung, and W. Lee, Combust. and Flame, 109, 266281 (1997).

6. D. X. Du, H. Wang, and C. K. Law, Combust. and Flame, 113, 264-270 (1998).

7. B. R. Stanmore, J. F. Brilhac, and P. Gilot, Carbon, 39, 2247-2268 (2001).

8. http://www.sootgenerator.com

9. S. P. Girling, C. D. Hurley, J. P. Mitchell, and A. L. Nichols, Aerosol Science \& Technology. v 13 n 1, 8-19 (1990).

10. T. G.Cleary, G. W. Mulholland, L. K. Ives, R. A. Fletcher, and J. W. Gentry, Aerosol Science and Technology, v16, 166-170 (1992).

11. http://www.palas.de/engl/produkte/trockd.htm

12. D. Kayes and S. Hochgreb, SAE Technical Paper Series 982601 (1998).

13. B. R. Graskow, D. B. Kittleson, I. S. Abdul-Khalek, M. R. Ahmadi, and J. E. Morris, SAE Technical Paper Series, 980528 (1998). 
14. G. E. Andrews, S. Abdelhalim, and P. T. Williams, SAE Technical Paper Series, 931003 (1993).

15. Health Perspectives. Understanding the Health Effects of Components of the Particulate Matter Mix: Progress and Next Step., Health Effects Institute (April 2001).

16. H. G. Wagner, Proc. Combust. Instit., 17, 3-19 (1979).

17. I. Glassman, Proc. Combust. Instit., 22, 295-311 (1988).

18. J. Du, and R. L. Axelbaum, Combust. and Flame, 100, 367-375 (1995).

19. O. Angrill, H. Geitlinger, T. Streibel, R. Suntz, and H. Bockhorn, Proc. Combust. Instit., 28, 2643-2649 (2000).

20. F. Xu, G. M. Faeth, Combust. and Flame, 125, 804-819 (2001).

21. D. R. Snelling, F. Liu, G. J. Smallwood, and O. Gulder, Combustion \& Flame. v 136 n 1-2, 180-19022 (2004).

22. R. Axelbaum, and C. K. Law, Proc. Combust. Instit., 23, 1517-1523 (1990).

23. O. Gulder and D. Snelling, Combust. and Flame, 92, 115-124 (1993).

24. C. R. Shaddix and K. C. Smyth, Combust. and Flame, 107, 418-452 (1996).

25. B Bedat and R. K. Cheng, Combust. and Flame, 107 (1-2) (1996) 13-26 (1996).

26. H. Tang, E. A. Lewis, D. J. Eatough, R. M. Burton, and R. J. Farber, Atmos. Environ.,28, 939-947 (1994).

27. C. J. Damm, D. Lucas, R. F. Sawyer, and C. P. Koshland, Appl. Spectrosc., 55, 1478$1482(2001)$. 
28. C. J. Damm, Excimer Laser Fragmentation Fluorescence Spectroscopy for Real-time Monitoring of Combustion Generated Pollutants, Ph.D. Thesis, University of California at Berkeley (2001).

29. J. S. MacDonald, S. L. Plee, J. B. D'Arcy, and R. M. Schreck, SAE Technical Paper Series, 800185 (1980).

30. S. L. Plee and J. S. MacDonald, SAE Technical Paper Series, 800186 (1980).

31. D. E. Hall, C. L. Goodfellow, H. J. Guttmann, J. Hevesi, J. S. McArragher, R. Mercogliano, M. P. Merino, T. D. Morgan, G. Nancekievill, L. Rantanen, D. J. Rickeard, D. Terna, P. J. Zemroch, and P. Heinze, A Study of the Number, Size, and Mass of Exhaust from European Diesel and Gasoline Vehicles Under SteadyState and European Driving Cycle Conditions., CONCAWE Automotive Emissions Management Group, Report No. 98/51 (1998).

32. C. S. Stipe, B. S. Higgins, D. Lucas, R. F. Sawyer, and C. P. Koshland, Proc. Combust. Instit., 29, 2767-2774 (2002). 


\section{Figure Captions}

Figure 1: The flow reactor used to produce combustion-generated soot particles. Methane and nitrogen flow through the center flame holder in the downward direction, combustion air flows in the annular region between the methane and the outer quartz tube. The resulting flame is cylindrical in nature.

Figure 2: Ten consecutive SMPS scans are shown as dNumber/dlogDp versus aerodynamic diameter. The total number concentration of particles has a standard deviation of $3.7 \%$.

Figure 3: The effect of nitrogen dilution of the methane jet on the size distribution of soot particles.

Figure 4: Diluting the fuel jet from 0 to $40 \%$ shifts the mean particle diameter from 60 to $190 \mathrm{~nm}$. The number concentration of particles remains relatively constant with 0 to $35 \%$ nitrogen dilution.

Figure 5: The effect of equivalence ratio on the size distribution of the soot particles.

Figure 6: The effect of equivalence ratio on the soot particle mean diameter and number concentration. As the fuel to co-flow air ratio is made more rich, the mean 
diameter shifts from 50 to $250 \mathrm{~nm}$. This case is dissimilar to the nitrogen dilution case in that the number concentration continuously increases.

Figure 7: The achieved and possible mass concentrations and mean particle diameters for the inverted, co-flow, non-premixed flame. The achievable particle sizes and concentrations are the area designated by the diagonal lines, and the sizes and concentrations for Diesel, spark-ignited, and atmospheric particles are the dot filled areas. 


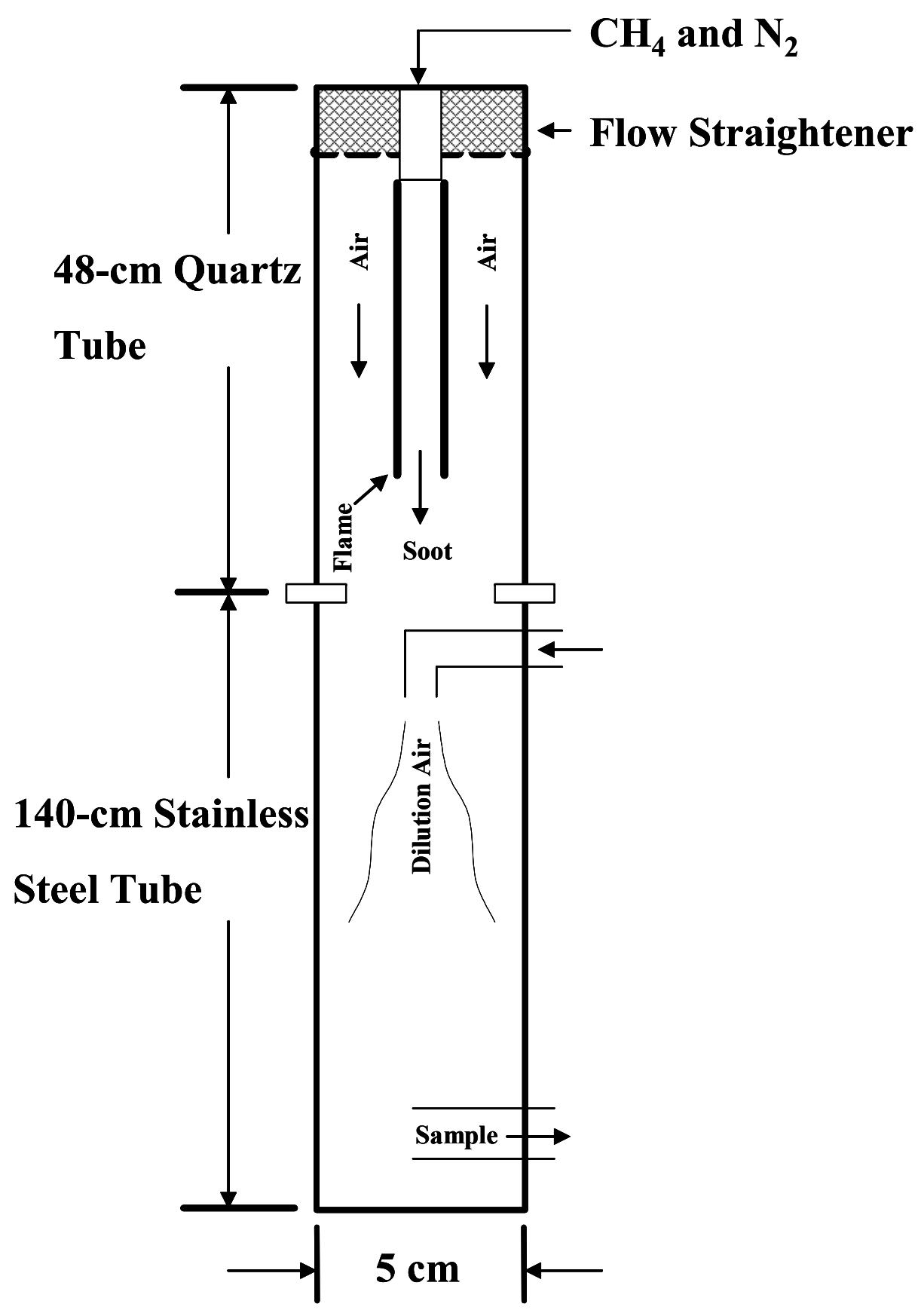

Figure 1 


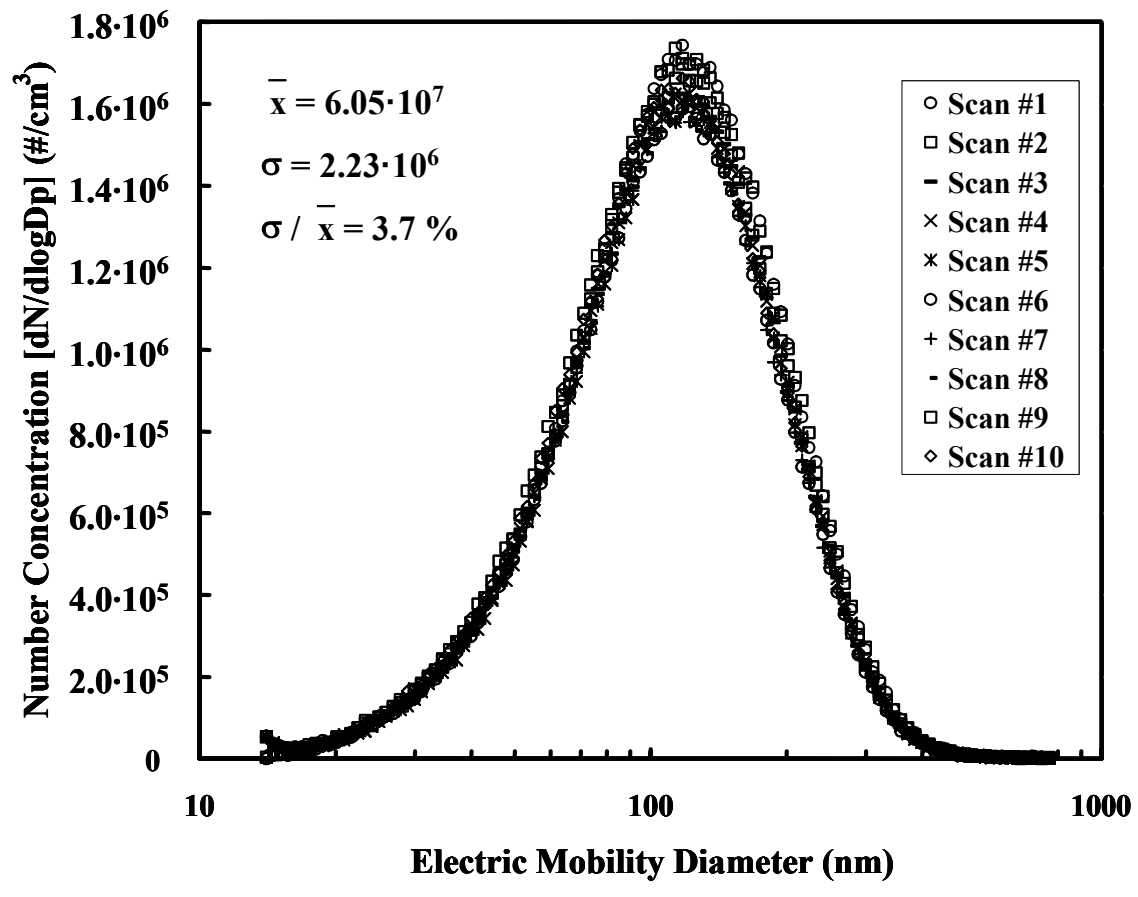

Figure 2 


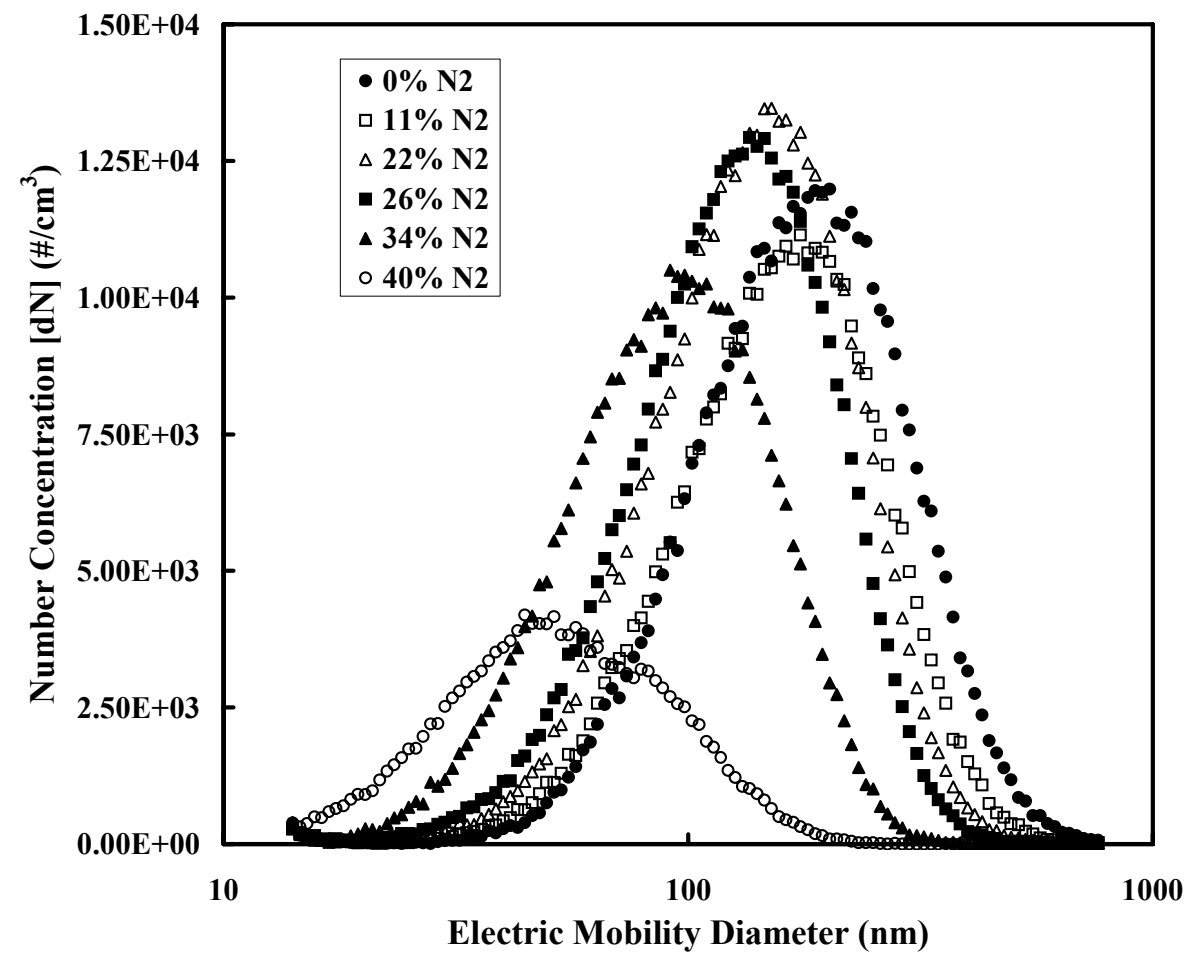

Figure 3 


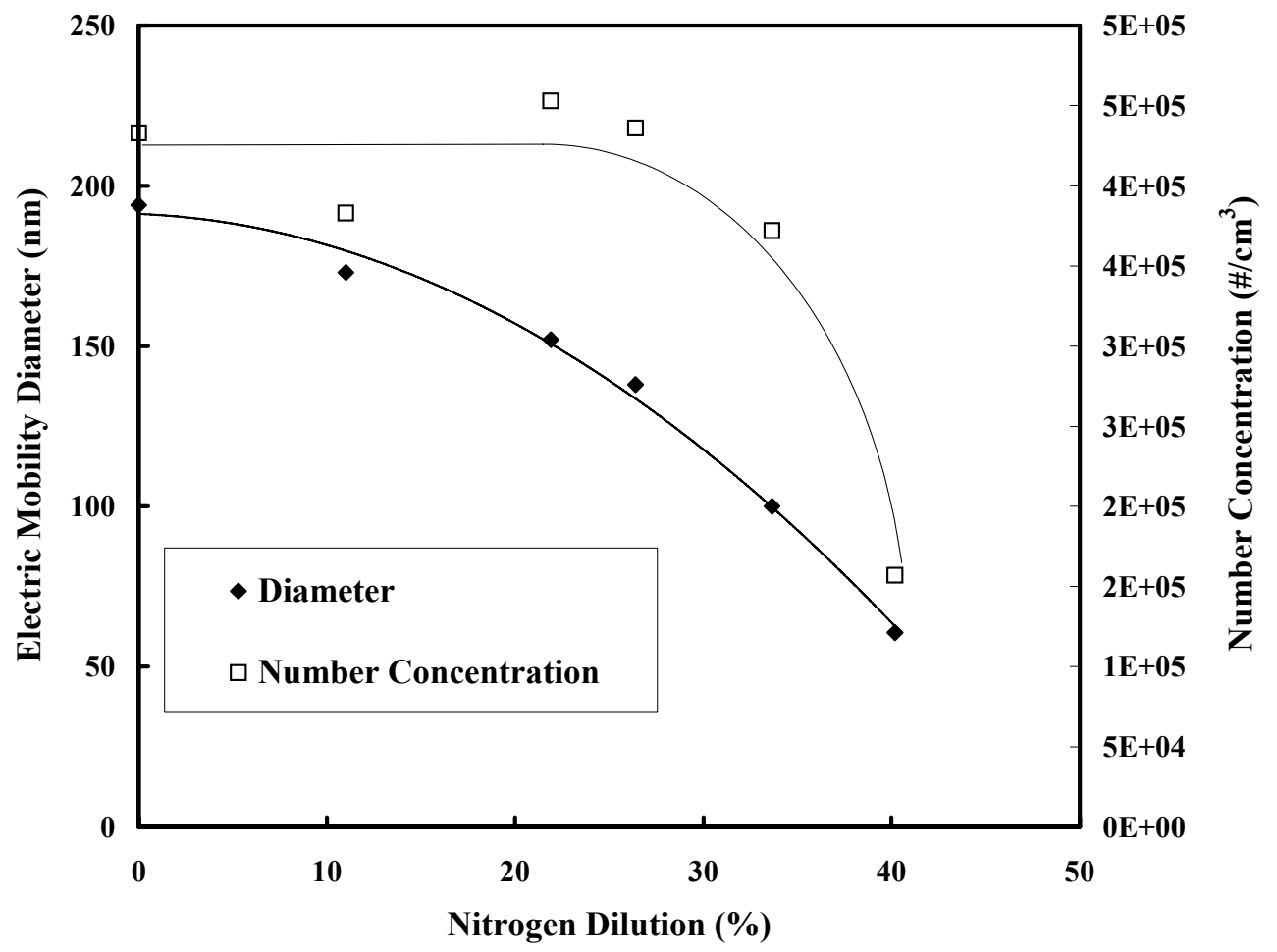

Figure 4 


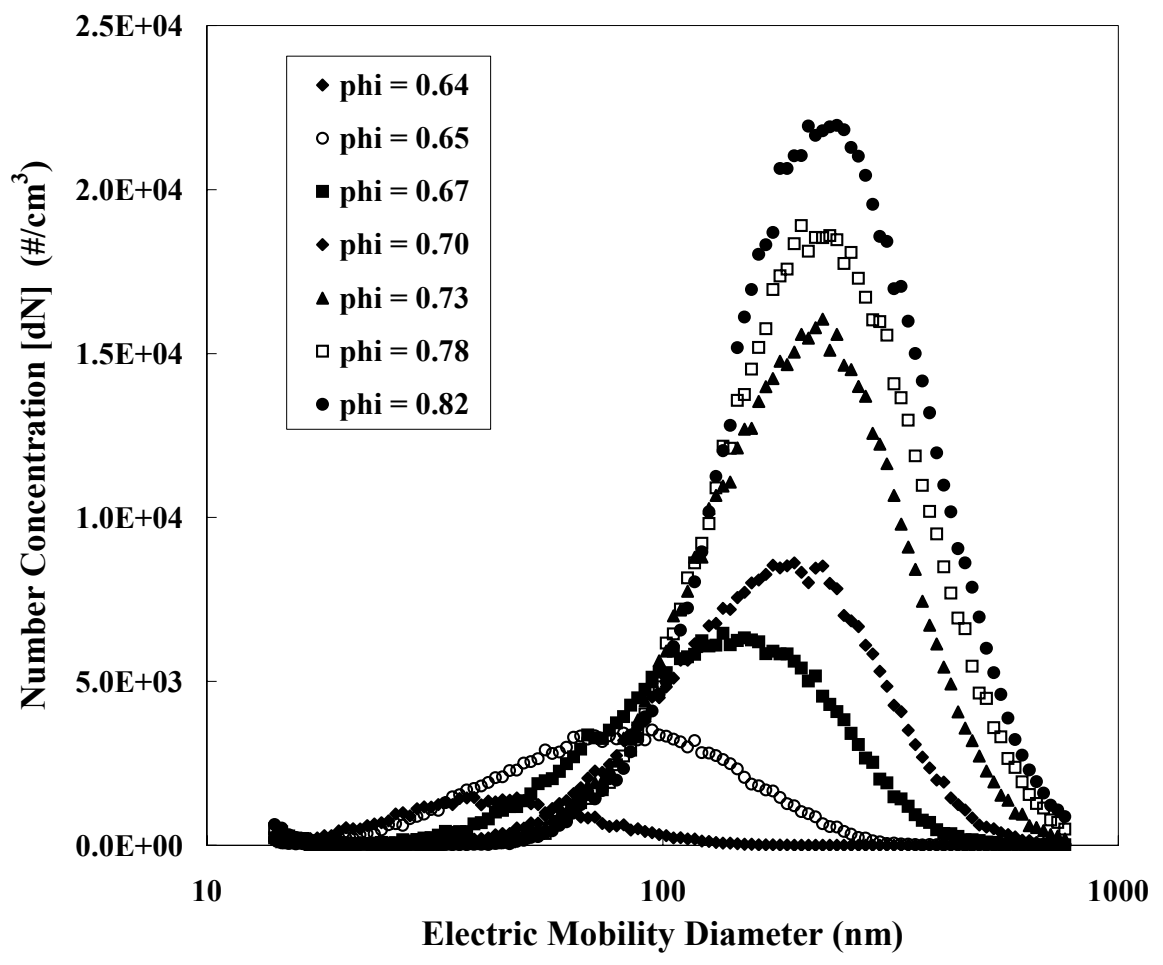

Figure 5 


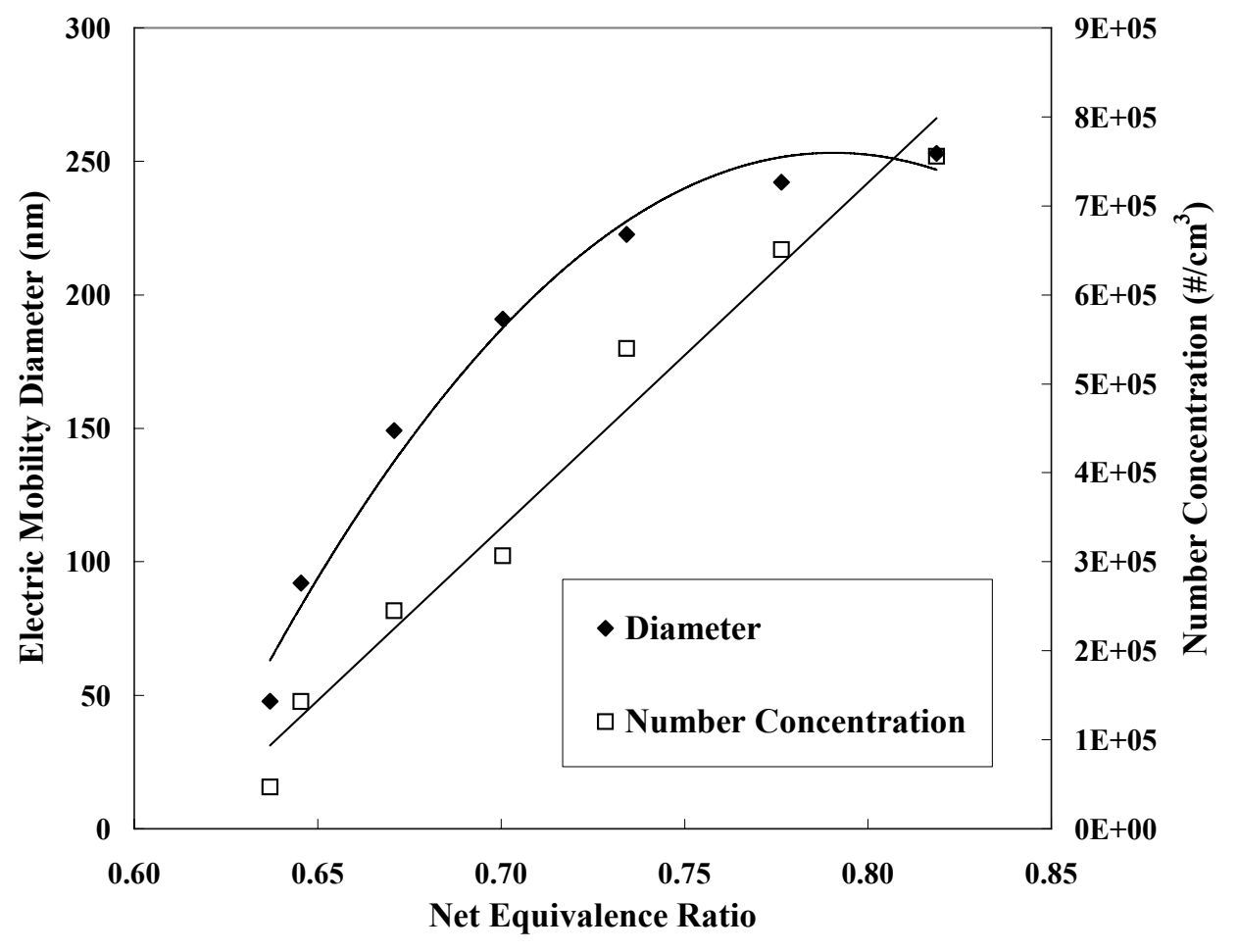

Figure 6 


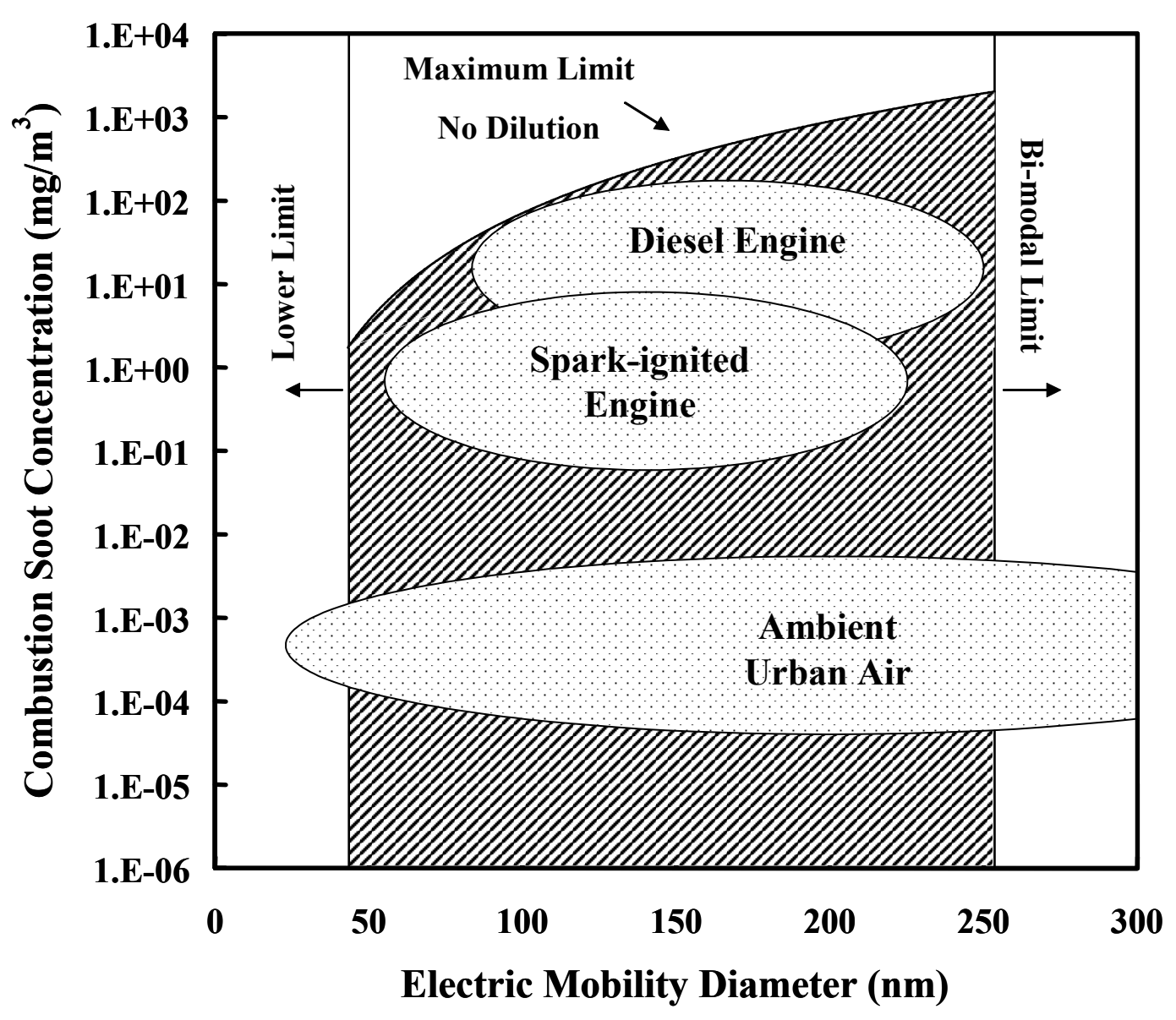

Figure 7 